\title{
Stereotyped adjunctive pecking by caged pigeons
}

\author{
WILLIAM L. PALYA \\ Jacksonville State University, Jacksonville, Alabama 36265 \\ and \\ JAMES P. ZACNY \\ West Virginia University, Morgantown, West Virginia 26506
}

\begin{abstract}
The behavior of 77 pigeons maintained at $80 \%$ of their free-feeding weights in open-wire battery cages was monitored 16 times a day by observers for up to 285 days. Five distinct types of stereotyped behaviors were operationally defined. One of these behaviors, "spot pecking," clearly predominated. Forty-nine of the 77 pigeons were observed spotpecking on at least $25 \%$ of the days they were observed, and several pigeons emitted more than 50,000 spot pecks per day. This occurred in spite of the total absence of any explicit reinforcer. A series of three experiments demonstrated that the great majority of spot pecks occurred in the hours immediately after feeding, that only food-deprived birds spot pecked, and that the behavior of adjacent birds influenced the rate of acquisition of stereotypes. Difficulties with labeling spot pecking as superstitious, respondent, or mediating are discussed. It is suggested that spot pecking be classed as an "adjunctive" behavior.
\end{abstract}

There has recently been a growing interest in behaviors that are anomalous within the operant paradigm, and in the nonarbitrary way these behaviors participate in functional relationships, as shown by the work of Breland and Breland (1961, 1966), Brown \& Jenkins (1968), Falk (1971), and Staddon (1977). The findings of these studies are seen as potential explanations for other data (e.g., Schwartz \& Gamzu, 1977) and as phenomena to be understood in their own right (e.g., Falk, 1977). In either case, the development of a broader and more detailed data base concerning these anomalous behaviors should increase the predictability of behavior in general by shedding light on how both phylogenetic and ontogenetic variables affect behavior (Kuo, 1967). It is apparent that substantial advancement in the understanding of behavior requires documentation of the diversity of behavior.

The casual observation of food-deprived pigeons in their home cages reveals reliable stereotyped pecking without apparent consequence or apparent eliciting stimulus. The controlling variables of pecking in a simple context such as the home cage may bear importantly on understanding data collected in other

The authors gratefully acknowledge the contributions of J. Kenny, P. Hurst, R. Yaracs, E. Palya, and I. J. Goodman. The authors are especially grateful to J. E. R. Staddon for his encouragement and constructive insights. Some of the data were presented at the 1979 Annual Meeting of the Southeastern Psychological Association in New Orleans. Requests for reprints should be sent to William L. Palya, Department of Psychology, Jacksonville State Universtiy, Jacksonville, Alabama 36265. situations. It was felt that a detailed study of this pecking was warranted because of the central role of pecking as a dependent measure in Pavlovian (Hearst \& Jenkins, 1974; Moore, 1973), consummatory (Zeigler, 1976), agonistic (Azrin, Hutchinson, \& Hake, 1966), and operant (Ferster \& Skinner, 1957) investigations.

An initial pilot study had noted sporadic stereotypes, and this resulted in an operational definition of the following five behaviors:

Spot pecking-This behavior consisted of repeated quick forward and backward head movements, sometimes with jaw movements (mandibulation), directed at or oriented toward a solid object, usually concentrated at a specific location, or "spot." This behavior appeared very similar to keypecking. Each quick forward and backward movement of the head was recorded as a spot peck (cf. Keiper, 1969; Sargent \& Keiper, 1967).

Air pecking-This behavior consisted of repeated quick forward and backward head movements sometimes with mandibulation, or of mandibulation alone away from any solid object. It apparently was not directed at or oriented toward any object, but it did tend to be concentrated in a specific direction. This behavior often included a rapid wide opening and closing of the beak. Each quick forward and backward movement of the head or beak opening was recorded as a response.

Food-cup pecking-This class included pecking in or on the food cup when the cup was apparently empty or when it contained only a small amount of 
pellet dust. This behavior was essentially identical to spot pecking, but was directed at the food cup rather than some other arbitrary spot in the cage. This behavior was recorded in the same way as spot pecking. Although food-cup pecking is essentially identical to spot pecking, these data were recorded separately in the event that analysis were to subsequently determine it to be a different class of behavior from spot pecking.

Water-cup behavior-This category consisted of various behaviors directed to the water, other than an incisive immersion of the beak accompanied by throat pumping ("drinking"). This class included splashing or sweeping the immersed beak in the water; dipping the beak in water and then tracing a relatively fixed path close to the floor with the beak, often accompanied by mandibulation; and dipping the beak in water and then engaging in such other behaviors as preening. These behaviors were reminiscent of behaviors which occur in free-ranging pigeons when in a small pool of water. Each contact of the beak with the water was counted as in instance of water cup behavior.

"Other" stereotypes-This category included prolonged occurrences of oriented fixed patterns of body movements other than pecking, such as head swinging, typically from a stationary position and oriented in an unusual direction, such as to the floor or to a corner of the cage. Mandibulation often occurred with this behavior. Each sequence was counted as a response.

The selected behaviors were obvious and very different from agonistic interactions, such as swinging the outstretched head and body forward; courting behavior, such as bowing and pacing; and the "typical" behaviors of birds, such as sitting relatively motionless oriented toward the front of the cage or preening.

The data recorded in the pilot study indicated that, in spot pecking there was typically a clear cluster of pecking to a particular location. These were generally single locations, were stable for each bird, and were generally less than $3 \mathrm{~cm}$ in diameter.

The present investigation observed pigeons in their home cages and recorded instances of pecking and other similar stereotypes or adjunctive behaviors while several changes were made with respect to their access to food and with respect to the behavior of adjacent birds.

The intent of the investigation was to document the predominant behavior, which was spot pecking, and to identify its controlling factors rather than to develop an extensive list of all stereotypes and their possible differential controlling factors. In general, therefore, only spot-pecking data are presented, even though the other classes of behavior listed typically exhibited the same functional relationships as spot pecking.

\section{GENERAL METHOD}

\section{Subjects}

Seventy-seven pigeons were observed in all. Thirty-six Birmingham Rollers and six wild pigeons had been previously exposed to 200 sessions of discrete stimuli paired with imminent presentation of response-independent food. These birds were of undetermined sex and approximately 2 years old. An additional 35 Birmingham Rollers had no experimental history and had been previously maintained in a loft. They were of undetermined sex and approximately 1 year old.

\section{Apparatus}

The pigeons were housed in a windowless animal room in individual open-wire cages. The dimensions of each individual cage were $44 \times 27 \mathrm{~cm}$ wide $\times 27 \mathrm{~cm}$ high. Eleven horizontally contiguous cages connected together formed a battery (Palya, 1977). Except for the end cages, which were in a corner, the line of sight was unrestricted to the right, left, and front. Four batteries, mounted above one another, were used to house the birds with previous keypeck experience. Three batteries that were similarly mounted on the adjacent wall were used to house the experimentally naive birds. The two groups of cages were therefore mounted perpendicularly to each other. The temperature of the pigeon room was marginally controlled by a common building-wide heating system and varied with the outside temperature from approximately $10^{\circ}$ to $30^{\circ} \mathrm{C}$.

\section{Procedure}

Two-hundred-cubic centimeter glass jars were used as food and water cups. They were mounted at a $45 \mathrm{deg}$ angle in front of each cage. The water cups were always available and held about $125 \mathrm{cc}$ of water. The typical free-feeding maintenance procedure was to keep the food cup about half full to minimize spillage. The cups therefore contained approximately $60 \mathrm{~g}$ when "full." The food was a pelletized chicken laying mash obtained locally. Food was provided and the water bottles changed or refilled at the same time for all birds in the animal room. This servicing occurred only at the scheduled feeding time. In order to minimize the effects of the light-dark cycle on feeding behavior (Palya, 1976), the animal room was lighted at all times. The criterion for all phase changes was visually stable records for 5 consecutive days.

Data were obtained by the "scan" method (Simpson \& Simpson, 1977). It involved observing each pigeon once each hour and recording the occurrence of the selected stereotypes. The observer entered the animal room, waited unobtrusively for $1 \mathrm{~min}$, and then systematically looked at each pigeon in succession. The presence or absence of each stereotype in each bird was recorded. The observer was visible to the pigeons. A characteristic of the scan method is that the probability of a behavior being detected is positively related to its frequency of occurrence. It is improbable, therefore, that a sporadically occurring behavior would regularly occur during an observation period (Fagen \& Goldman, 1977).

An additional "rate" method was used when indicated. This method involved counting occurrences of a stereotype in a particular bird with a hand-operated mechanical counter for the duration of the sample period. This rate method provided data on the frequency of stereotypes within birds. A series of simultaneous observations by the four observers used to record the data for the present study revealed that the greatest difference between any two observations was not greater than $5 \%$. The observers were visible to each other during these reliability tests.

\section{EXPERIMENT 1}

The pilot study had indicated that spot pecking was topographically similar to the behavior that occurred during eating (Zeigler, 1976), and that the amount of 
spot pecking was greatest in the afternoons, when many of the birds had been fed. The effect of feeding time on the temporal distribution of spot pecking was therefore assessed.

\section{Method \\ Subjects \\ Forty-two birds were used in Phases A, B, and C: 36 keypeck- experienced Birmingham Rollers and 6 keypeck-experienced wild pigeons. A subsequent probe used 24 naive birds. Therefore, a total of 66 birds were observed during the probe condition. All birds were maintained at approximately $80 \%$ of their free-feeding weights throughout this experiment.}

\section{Apparatus}

The four banks of open-wire battery cages mounted above one another along one wall were used in Phases $\mathrm{A}, \mathrm{B}$, and $\mathrm{C}$. The three additional banks mounted on the adjacent wall were also used during the probe.

\section{Procedure}

Phase A. The feeding time was fixed at $1600 \mathrm{~h}$ for all birds in the animal room. Observations were taken at the beginning of every hour between 0800 and $2300 \mathrm{~h}$ using the scan method. Phase A lasted 31 days.

An additional recording period was implemented in order to obtain a detailed and complete 24-h record of spot pecking for one bird. This recording period started at 0700 on the 19th day. One bird (No. 18), selected for its reliably high rate, was observed continuously for $24 \mathrm{~h}$. Each spot peck was recorded by hand with a mechanical counter.

Phase B. To assess the extent to which spot pecking was controlled by events surrounding the actual feeding time rather than other variables such as time of day or intensity of lab activity, feeding time was shifted by $12 \mathrm{~h}$ to $0400 \mathrm{~h}$. All other conditions were identical to Phase A. This phase lasted for 10 days.

In addition, the rate method was used to obtain detailed 1-min spot pecking counts each hour for each of the 42 birds for one 24-h period beginning at $0420 \mathrm{~h}$ on the 9th day of the phase. This provided a broader-based estimate of the total number of spot pecks each bird emitted per day. Following the initial scan observation of all 42 birds each hour, the detailed rate observations were done in a fixed, sequential manner. During the lst minute, the first pigeon was observed; during the 2 nd minute, the second pigeon was observed, and so on until all 42 birds had been observed $42 \mathrm{~min}$ later.

Phase $C$. In this phase, the birds were returned to the baseline feeding at $1600 \mathrm{~h}$ as in Phase A. This phase lasted for 10 days.

Probes. Two probes were implemented after an additional 24 naive birds had been added to the animal room. These probes were to determine which aspects of the feeding situation were responsible for spot pecking. The probes were conducted after all 66 birds had been in the animal room and exposed to being fed as a group at $1600 \mathrm{~h}$ for approximately 3 months. All birds in the animal room were then exposed, for 7 days, to the standard baseline conditions of $80 \%$ deprivation and feeding at $1600 \mathrm{~h}$ daily to provide baseline data for the probe.

Probe 1 consisted of a simple procedural change which occurred for 1 day. At the 1600 -h feeding time, each bird's daily ration was scooped from a grain bucket as usual and then surreptitiously dumped back into the bucket. The empty food cup was then replaced in front of the cage. All birds subsequently were fed normally after the $2300-h$ observation that night.

Following 5 additional days of baseline conditions, Probe 2 was implemented. During Probe 2, none of the normal activities typically associated with feeding time were present at $1600 \mathrm{~h}$. The conditions and behavior of the observer were those of a simple observation period rather than the feeding period. All birds subsequently were fed normally after the 2300 -h observation that night.

\section{Results and Discussion}

The number of birds spot pecking was well controlled by the feeding time. This can be seen in the left column of Figure 1, which presents the percentage of all 42 birds spot pecking at each hour for each of the three phases. The individual lines in each frame represent the percentage of birds spot pecking at each hour for each of the last 5 days of that phase.

Few birds spot pecked in the hours prior to feeding. Immediately following feeding, there was a dramatic increase in the incidence of spot pecking. Subsequently, the number of birds spot pecking slowly diminished. Typically, few birds were spot pecking $5 \mathrm{~h}$ after food presentation, even though there was a somewhat higher incidence of spot pecking throughout the day in the phase which provided food at $0400 \mathrm{~h}$. The temporal distribution of spot pecking shifted within 1 day following a shift in feeding time. Casual observation indicated that spot pecking typically was initiated within 5 min of exhausting the food ration; and that if spot pecking occurred at all, it was typically initiated within 30 min of eating.

The detailed records are presented in the right column of Figure 1 with their respective phases. The detailed record obtained from Bird 18 over a 24 -h period, Figure 1D, demonstrated a marked increase in the number of spot pecks immediately after feeding, and the characteristic subsequent cessation within a few hours. A total of 37,178 spot pecks were recorded for this bird during the 24-h observation. Approximately $90 \%$ of these occurred between 1600 and $2000 \mathrm{~h}$. This was an average rate of 2.3 responses/ $\mathrm{sec}$ for the 4-h period.

Figure $1 \mathrm{E}$ presents the hourly spot-pecking rates of each bird that spot pecked during the 24 -h detailed observation of all birds. The records are arranged by shape into three columns and compressed to minimize the size of the frame. The height of each line indicates the spot-pecking rate for that bird during each hourly 1 -min observation period. Thirteen birds did not spot peck at all. In 13 birds, spot pecking was confined to a single bout, while 16 birds spot pecked intermittently throughout the day. An estimate was made of the total spot pecks per day in the 29 that spot pecked at least once. The hourly frequency for each bird was estimated using the mean of the count for that and the subsequent hour. Considering only these birds, there was an estimated mean of 19,608 pecks per day per bird, and there was an estimated mean of 27 pecks per minute per bird between 0400 and $0900 \mathrm{~h}$.

Figure $1 \mathrm{~F}$ provides an indication of the day-to-day stability of spot pecking within birds. This figure depicts how many days each bird spot pecked out of the last 5 days of Phase $\mathrm{C}$ at each hour. The records are arranged by shape into three columns and compressed to minimize the size of the frame. Of the 

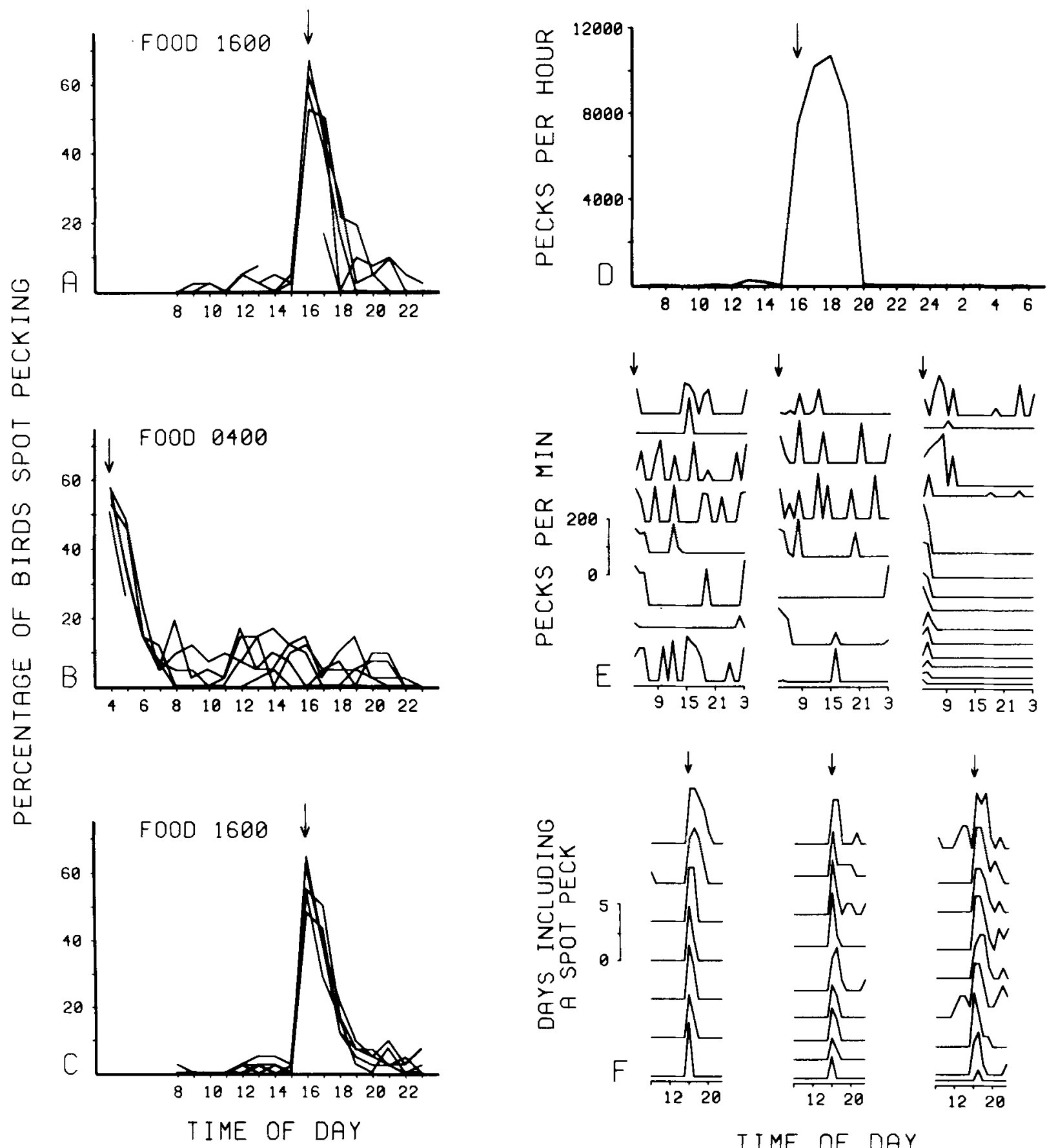

\section{TIME OF DAY}

Figure 1. The left-hand column presents the percentage of pigeons spot pecking at each hour in Phases $\mathbf{A}, \mathbf{B}$, and $\mathrm{C}$ of Experiment 1 . The right-hand column presents the hourly records of individual pigeons. The top frame (D) provides a complete record of each peck emitted by one bird for $24 \mathrm{~h}$. The middle frame (E) presents a 24-h record of hourly peck counts for each bird that spot pecked. The bottom frame (F) indicates the number of days on which each bird pecked during each hourly sample for the last 5 days of the phase. The arrows associated with each frame indicate the feeding time. See text for further explanation.

25 birds that spot pecked, few birds ever spot pecked before the availability of food. However, as indicated by the height of each function, almost all of these birds always spot pecked following the 1600 -h feeding each day. For birds that spot pecked for more than $1 \mathrm{~h}$, there was a gradual decrease in the percentage of days on which spot pecking occurred as the time since feeding increased.
Records from the probes are presented in the two frames of Figure 2. The solid lines show the percentage of birds spot pecking for each of the five days of base conditions immediately preceding the probe day. The broken lines indicate the percentage of birds spot pecking at each hour of the probe day.

As indicated by the dotted line in the first frame, there was an increase in spot pecking both at $1600 \mathrm{~h}$, 

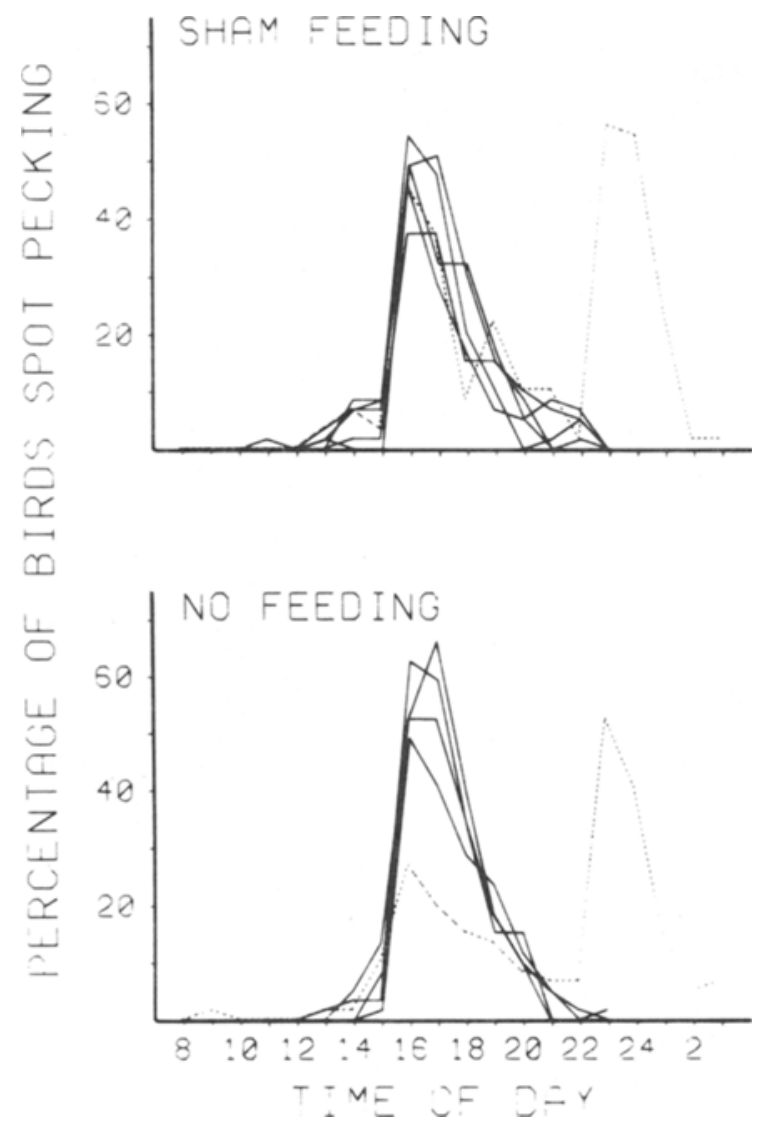

Figure 2. The two frames indicate the percentage of birds spot pecking at each hour for the 5 days preceding a probe (solid lines) and at each hour of the 2 probe days (broken line). The upper frame illustrates the effects of sham feeding, while the bottom frame illustrates the effects of no feeding.

when only the sham feeding occurred, and at $2300 \mathrm{~h}$, when the complete feeding procedure occurred. The behavior following sham feeding even showed the characteristic slow decrease in percentage of birds spot pecking over the subsequent $5 \mathrm{~h}$. The spot pecking generated by this sham feeding can be compared to both the preceding 5 days and the subsequent feeding that day, at $2300 \mathrm{~h}$. The functions are essentially identical.

As indicated by the dotted line in the lower frame of Figure 2, a moderate increase in spot pecking also occurred at $1600 \mathrm{~h}$, even after every attempt was made to remove anything differentially associated with feeding and to make the $1600 \mathrm{~h}$ observation period that day identical to all other observation periods. This increase in spot pecking indicated either an incomplete removal of relevant external stimuli or some internal timing mechanism which was differentially associated with the 1600 -h feeding time. The control of spot pecking by simple internal temporal factors would not be unusual (Ferster \& Skinner, 1957; Rusak \& Zucker, 1975) and would account for the occasional occurrence of spot pecking shortly before $1600 \mathrm{~h}$.
The data from the two probes are clear in indicating that it is not necessary for eating to occur in individual birds or even in the animal room for spot pecking to occur. It also indicates that somewhat arbitrary initial links which have regularly preceded food presentation in the past can be added to the sequence which precipitates spot pecking.

\section{EXPERIMENT 2}

Experiment 1 indicated that feeding time strongly controlled the temporal distribution of spot pecking. Experiment 2 therefore examined the impact of several different deprivation levels upon spot pecking.

\section{Method}

\begin{abstract}
Subjects
Nine birds were selected on the basis of the quantitative rate measures obtained during Experiment 1 . Three birds each were chosen as roughly matched exemplars of low, moderate, and high spot-pecking rates. One of each class was then assigned randomly to three groups such that each group had a low-, moderate-. and high-rate bird.

Two additional birds were also selected for detailed study, one because it did not perform any obvious stereotype and one because it performed an "other" stereotype forienting the head to the bottom of the cage and moving it back and forth while mandibulating). These 2 and the 58 other birds in the animal room were maintained at $80 \%$ of their free-feeding weights with daily feeding at $1600 \mathrm{~h}$, except during Phase $\mathrm{C}$, as noted.
\end{abstract}

\section{Apparatus}

The same seven banks of cages that were used in Experiment 1 were used.

\section{Procedure}

The general procedures with regard to servicing and observing the pigeons were the same as those of the previous experiment. In addition to the normal scan method of collecting data, a subsequent 1 -min response count was made, between the hours of 1300 and 2000 , in a fixed, sequential manner for each of the birds to obtain a detailed rate measure.

Phase A. Phase A was the initial baseline-data collection phase. All birds were maintained on the standard base conditions of $80 \%$ body weight and daily feeding at $1600 \mathrm{~h}$. This phase lasted for 17 days.

Phase B. Three deprivation conditions were implemented to determine the effect of varying deprivation levels. The birds in Group $70 \%$ were maintained at $70 \%$ of their free-feeding weights. The birds in Group $\mathbf{8 0 \%}$ were maintained at $80 \%$ of their freefeeding weights, and the birds in Group $90 \%$ were maintained at $90 \%$ of their free-feeding weights. During the scheduled feeding period, all pigeons were provided with the quantity of food that would result in the required body weights when they were weighed that night at $2310 \mathrm{~h}$. The 2 selected non-spot-pecking birds as well as the remaining 58 birds in the animal room continued to be maintained at $80 \%$ of their free-feeding weights with daily feedings at $1600 \mathrm{~h}$. This phase lasted for 20 days.

Phase C. All birds in the animal room were provided with free access to food. All other conditions were identical to those of the preceding two phases. Food and water cups continued to be serviced only at $1600 \mathrm{~h}$. This phase lasted 12 days.

Phase D. This phase examined the effect of mild deprivation on the occurrence of spot pecking. Three deprivation levels were assigned randomly to the three previously formed groups. Group Every 1 had free access to food from 1600 to 2300 h every day. Group Every 2 had free access to food from 1600 to $2300 \mathrm{~h}$ 
every 2 nd day, with no food available on the intervening day. Group Every 3 had free access to food from 1600 to $2300 \mathrm{~h}$ every 3 rd day, with 2 intervening days without food. This phase lasted 20 days.

Phase E. Phase E changed the conditions to which the three groups of birds were exposed. Group Every 1-4, which had been fed every day, now had access to food every 4th day, with no food during the 3 intervening days of deprivation. The feeding period for this group was from 1600 to $2300 \mathrm{~h}$ every 4 th day. The conditions of the other two groups were reversed. Group Every 2-3, which had been fed every 2 nd day, now were fed every 3 rd day, with no food during the 2 intervening days of deprivation. Group Every 3-2, which had been fed every 3rd day, now were fed every other day, with no food during the intervening day of deprivation. This phase lasted 18 days.

\section{Results and Discussion}

The baseline conditions of Phase A continued to produce the same distribution of spot pecking as was previously demonstrated in Experiment 1. Figure 3 presents the effects of percentage body weight on both the hourly rate of spot pecking and the number of days on which each bird spot pecked for each hour. The data are for the last 5 days of each phase. The first and third columns present the data for increased and decreased deprivation levels, while the center column presents the same measures for when the deprivation level had not been changed.

The frames with histograms present the spot-pecking rate for each bird under baseline conditions of $80 \%$ body weight (solid bars) and under the deprivation conditions of $70 \%, 80 \%$, or $90 \%$ body weight (open bars), respectively. Data for the rate measure were obtained only between 1300 and $2000 \mathrm{~h}$. This rate measure is the "local" or "running" rate, and is based on only those observations which included an instance of spot pecking. As can be seen in these frames, not only was there no consistent difference between the baseline conditions and Phase B, but there was only a moderate change in rate throughout the day during either phase. These frames indicate that spot pecking generally occurs at a relatively constant local rate for a particular bird.

The lower frames in Figure 3 provide the number of days on which each bird pecked under baseline conditions of $80 \%$ body weight (solid lines) and under the deprivation conditions of $70 \%, 80 \%$, and $90 \%$ body weight (broken lines), respectively. These frames indicate the number of days each bird spot pecked during each hour for the last 5 days of the phase. As can be seen, there was little difference between the Phase A baseline and Phase B in the dayto-day probability of spot pecking in the birds maintained at $80 \%$ or $90 \%$ body weight during Phase B. However, the birds reduced from $80 \%$ body weight to $70 \%$ body weight did spot peck slightly more often when at $70 \%$ body weight. These birds spot pecked during more observation periods throughout the day and they also spot pecked on more of the last 5 days at those times.
The detailed observations of the two birds which did not spot peck indicated that there was little change in the rate or frequency of their behavior in the 38 days they were exposed to feeding at $1600 \mathrm{~h}$ and being maintained at $80 \%$ body weight.

When all birds were placed on free feeding in Phase C, virtually all stereotypes were abolished in all birds within 1 day. The scan data for all birds in the animal room indicated that in the last 5 days of Phase $\mathrm{C}$ there were only 11 recorded stereotypes of any kind out of the 5,280 possible instances on which a stereotype could have been recorded. These data were obtained from 66 birds. Three had died earlier.

Phases D and $\mathrm{E}$ indicated that, in the $7 \mathrm{~h}$ following a missed feeding period, spot pecking occurred at approximately the same frequency following $17 \mathrm{~h}$ (first missed feeding), $41 \mathrm{~h}$ (second missed feeding), or $65 \mathrm{~h}$ (third missed feeding) of deprivation. They also indicated that spot pecking did not occur at less than $17 \mathrm{~h}$ of deprivation or during the hours of free access to food on the days food was available.

\section{EXPERIMENT 3}

One factor which had not been systematically controlled up to this point was the behavior of the other birds in the animal room. Several observations had suggested that the behavior of other birds was potentially important in determining the emergence and topography of stereotypes. They included the relatively low rates of spot pecking during the initial pilot study when the birds were not fed at the same time, and the occurrence of strikingly similar stereotypes in adjacent birds.

Two types of control were examined in this experiment. They were the effects of stereotyping in adjacent birds on the acquisition of stereotyped behavior in naive birds, and the effects of abolishing stereotypes in adjacent birds on the previously reliable stereotypes of the center birds.

\section{Subjects}

\section{Method}

Data are presented from a total of 28 birds. Four sets of 3 matched birds each and four sets of 2 matched birds each were selected from the 66 birds that remained from the first two experiments. Three birds had died during the previous experiment. The eight sets of birds were matched with respect to type and frequency of stereotype. In addition, 8 Birmingham Rollers, approximately 2 years old, of undetermined sex, and without keypeck experience, were used. These naive birds had been maintained in a loft at free feeding for at least 1 year, and had not been previously maintained in cages. The remaining 46 birds from the previous experiments were housed in the animal room. They continued to be maintained at $80 \%$ body weight and fed at 1600 daily.

\footnotetext{
Apparatus

The same seven banks of cages from Experiments 1 and 2 were used. The four banks of cages mounted on one wall were modified. Eight sets of three horizontally contiguous cages were separated from the other cages in the bank and from each other
} 
$70 \%$

$80 \%$
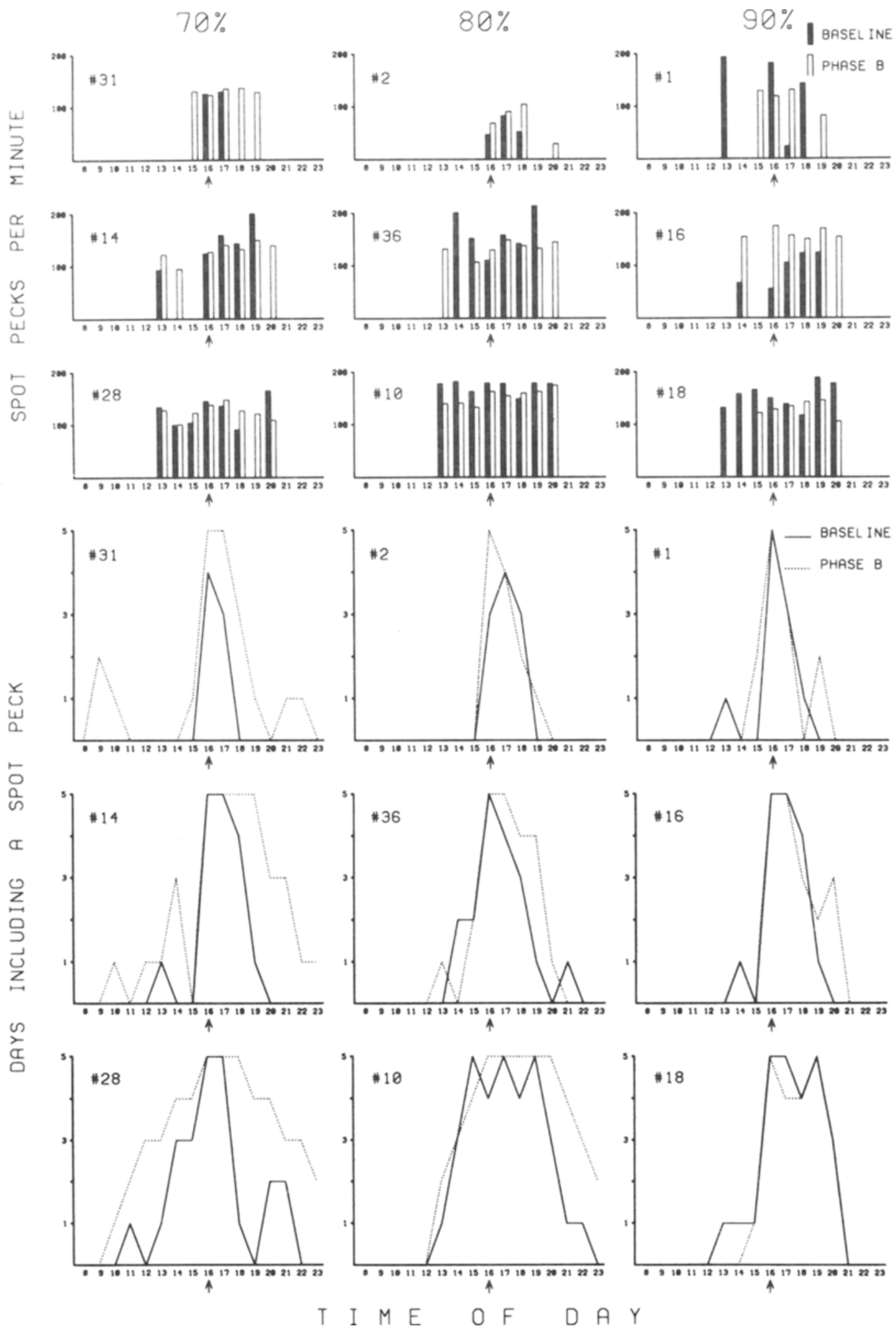

$T$ I $M E \quad O F \quad D A$

Figure 3. The upper frames containing histograms present the local spot-pecking rate for each bird under baseline conditions of $80 \%$ body weight (solid bars) and under the deprivation conditions of $70 \%, 80 \%$, or $90 \%$ body weight (open bars), respectively. The lower frames provide the number of days on which each bird pecked during each hourly sample under baseline conditions of $80 \%$ body weight (solid lines) and under the deprivation conditions of $70 \%, 80 \%$, and $90 \%$ body weight (broken lines) respectively. See text for further explanation. 
by opaque barriers and empty cages. The remaining cages were used to house the other pigeons maintained in the animal room.

\section{Procedure}

Phases A, B, C, and D with one group of birds and Phase E and $F$ with a different group of birds were run concurrently. Phases A and B examined the maintenance of stereotypes in birds when their flanking birds ceased to exhibit any stereotype.

Phase A (stereo-stereo-stereo). In this baseline phase, the four sets of three matched stereotyping birds each were placed in four of the three-cage sets. They were maintained for 17 days on the standard conditions of $80 \%$ body weight and feeding at $1600 \mathrm{~h}$

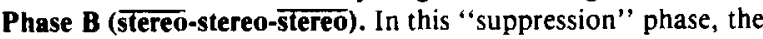
outer two birds in each of the groups used in Phase A were provided with free access to food, which immediately abolished stereotyping in those birds. The center birds continued to be maintained at $80 \%$ body weight with daily feeding at $1600 \mathrm{~h}$. This phase lasted 17 days.

Phase C (stereo-naive-stereo). This "retardation" phase was an attempt to assess whether the development of stereotypes was retarded when a newly caged naive bird was flanked by birds which did not exhibit any stereotypes. The four original center birds used in Phases A and B were therefore replaced with four naive birds. These birds were fed approximately $1 \mathrm{~g}$ each day until they reached $80 \%$ of their loft weights. They were then maintained at that weight with daily feeding at $1600 \mathrm{~h}$. The flanking birds continued to be provided free access to food, and therefore did not engage in stereotypic behavior. This phase lasted 19 days.

Phase D (stereo-naive-stereo). This "acquisition" phase initiated stereotyping in the flanking birds to monitor its effect on the behavior of recently caged birds. The naive center birds continued to be held at $80 \%$ of their free-feeding weights, while the flanking birds were reduced to, and maintained at, $80 \%$ body weight. The adjacent birds were fed approximately $1 \mathrm{~g}$ each day until they reached their $80 \%$ weights. The flanking birds engaged in stereotypic behavior within 2 days. This phase lasted 28 days.

The following two phases were conducted concurrently with Phases A, B, C, and D and used different birds. These phases were implemented to provide comparison data.

Phase E (stereo-naive-stereo). This "facilitation" phase examined the development of stereotypes in four naive birds, each flanked by two birds which reliably emitted the same stereotypes. Naive birds which had not been previously caged were placed between stereotyping birds that were maintained at $80 \%$ of their free feeding body weights. The difference between this phase and Phase D was the experience of the center birds. Phase D had center birds which had been caged between nonstereotyping birds for 19 days, while the naive birds in this phase had just been caged. These naive birds were fed approximately $1 \mathrm{~g}$ each day until they reached $80 \%$ of their loft weights. All birds were maintained thereafter on the standard base conditions of $80 \%$ body weight and feeding at $1600 \mathrm{~h}$ daily. This phase lasted 36 days.

Phase F (stereo-new-stereo). This "suppression" phase was an attempt to abolish the newly acquired stereotypes developed in the preceding phase (E) by terminating the stereotypes in the adjacent birds. This phase therefore complemented Phase B (stereostereo-stereo). In this case, however, the birds had newly acquired stereotypes rather than well-established ones. The flanking birds were provided with free access to food, which immediately terminated their stereotypes. All conditions were the same as those in effect during $P$ hase $B$. This phase lasted 28 days.

\section{Results and Discussion}

The behavior of adjacent birds had a dramatic effect on the acquisition time of stereotypes. Naive birds, reduced in body weight and maintained between two birds that reliably stereotyped, developed stereotypes within 5 days (Phase E: stereo-naive-stereo), whereas naive birds reduced in body weight and maintained

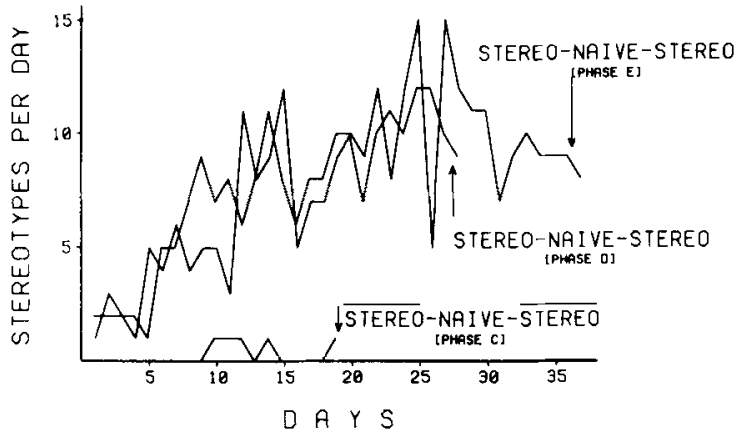

Figure 4. Each line represents the total number of instances of all stereotypes recorded each day for the three birds combined from Phase C, Phase D, and Phase E, respectively. Phase $\mathbf{C}$ exposed three naive birds to nonstereotyping adjacent birds, while Phases $D$ and $E$ each exposed three naive birds to stereotyping adjacent birds.

between two birds which did not emit sterotypes did not exhibit stereotypes within 19 days (Phase C: stereo-naive-stereo). These birds, which had not developed stereotypes within 19 days, subsequently developed reliable stereotypes when their adjacent birds were deprived and their stereotypes were restored (Phase D: stereo-naive-stereo).

Figure 4 illustrates these results. The total instances of stereotypes per day is represented by the height of the line for that phase. There were 16 observation periods each day for each of the four birds. Thus, the maximum number of stereotypes possible was 64 .

The topography of the acquired stereotype was not demonstrated to be under the control of the topography of the adjacent stereotype. Of the eight stereotypes, only two could be taken as similar to the behavior of the adjacent birds.

The phases which attempted to suppress stereotyping by abolishing stereotypes in adjacent birds indicated that terminating the stereotypes in adjacent birds had only a slight and transient disruptive effect on the stereotypes of the center birds. There was little effect on either the temporal distribution of the stereotypes or on the distribution of topography frequencies. Little permanent change occurred in the stereotypes with an extensive history in Phase B (stereo-stereo-stereo) or in the newly acquired stereotypes in Phase F (stereonew-stereo).

\section{GENERAL DISCUSSION}

The present study demonstrated that spot pecking is a reliable postfood behavior of deprived pigeons maintained in open-wire cages by daily group feedings at the same time of day, that it can be easily and completely abolished by providing the birds with free access to food, and that it is very stable in terms of its topography, focus, rate, and temporal distribution. In addition, it appears that social factors can facilitate or retard the development of stereotypes, 
and that at least some arbitrary stimuli that have been associated with feeding can come to control the behavior.

Of the 182,048 observations made during the investigation, 20,659 , or $11.3 \%$, contained an instance of a stereotype. Of these, $76 \%$ were spot pecks, $6 \%$ were air pecks, $4 \%$ were food-cup pecks, $8 \%$ were water-cup behaviors, and 5\% were "other" stereotypes. Forty-nine of the 77 pigeons were observed spot pecking on at least $25 \%$ of the days they were observed, and it was estimated that several pigeons emitted more than 50,000 spot pecks per day.

Spot pecking could be the result of several factors. Notions such as "boredom" (Hediger, 1955/1968; Nissen, 1956) or "a need to peck" (Levy, 1938; Maier \& Maier, 1970) are not at all consistent with the data. Little spot pecking occurred in the mornings, and none occurred when the birds were on free feeding. Postulating a periodic "boredom" cycle or "need-to-peck" cycle would rob these ideas of the little explanatory power that they may have.

The primary elicitor of spot pecking did not seem to be proprioceptive feedback from the preceding response. The detailed observation for all birds for $24 \mathrm{~h}$ (Figure $1 \mathrm{E}$ ) indicated many interruptions between periods of stereotypic behavior. In addition, casual observation indicated that spot pecking was only temporarily terminated by naturally occurring disturbances or by 1-h blackouts. Spot pecking was resumed shortly after the interruption was removed in either case.

It is also unlikely that operant or respondent reinforcement by food presentation is responsible for spot pecking in that it occurs after, rather than before, food presentation. The behavior that occurred before food presentation in the present study was quick sidestepping or darting back and forth across the front of the cage, vigorous thrusting of the head and body through small openings in the front of the cage, and wing flapping. If food presentation adventitiously reinforced the preceding response class, then stereotypes would have had an entirely different character than they did. Stereotypes generally involved the rapid repetition of some behavior, that had little general body involvement, and were often oriented in a direction other than the front of the cage. In addition, spot pecking occurred approximately $20 \mathrm{~h}$ before food presentation in the portion of the interval which was maximally removed from food. The delay of reinforcement and lack of discrimination which would therefore characterize spot pecking are not typical of operant behavior.

Respondent reinforcement by food presentation as an explanation for spot pecking suffers the same difficulty as operant reinforcement in that spot pecking occurs after food presentation. If spot pecking is assumed to consist of associatively conditioned components of eating, then its occurrence after food presentation is anomalous. Alternatively, spot pecking could be some respondent controlled by the long delay to the next feeding period signaled by exhausting the food ration (Duncan \& Wood-Gush, 1971). The occasional occurrence of spot pecking at $1500 \mathrm{~h}$ and during the probe, which skipped the feeding period, is then anomalous. Both of these periods would have been maximally associated with imminent food presentation.

A general-arousal interpretation of spot pecking also faces difficulties. To covary with spot pecking, general arousal would have to be relatively independent of deprivation levels less severe than $70 \%$ body weight and could not be positively correlated with time since feeding. A second problem for a generalarousal interpretation would be to account for the dramatic difference in the behaviors which occurred immediately before and several minutes after food presentation. In either case, special functions relating spot pecking to general arousal would be required which would undercut the usefulness of general arousal as an explanation.

Alternatively, the occurrence of spot pecking might be considered a mediating behavior. However, mediating behavior actually implies that it occurs throughout the interval and that it in some way modifies the reinforcement probability (Deadwyler \& Segal, 1965; Flynn \& Tedford, 1976; Segal \& Deadwyler, 1965). Stereotypes occur primarily immediately after food presentation rather than throughout the interval, and no behavior could modify reinforcement probabilitity, in that food presentation was noncontingent.

Spot pecking, polydipsia (Falk, 1961), and interim behavior (Staddon \& Simmelhag, 1971) all occur between food presentations. Falk (1971) presented a conceptual framework within which to integrate many of these divergent schedule-induced behaviors. He proposed that schedule-induced aggression, escape, pica, wheel running, air licking, and water consumption all exhibited common properties. He labeled this class of behaviors "adjunctive behavior." Adjunctive behaviors are maintained at a high rate by schedule parameters of the "generator schedule" which governs some other consummatory behavior. The similar functional properties include an increase followed by a subsequent decrease in the effectiveness of the generator schedule with increasing intermittence, increasing rates of adjunctive behavior with increases in deprivation level, occurrence of the behavior immediately after the consummatory behavior in the generator schedule, and an excessive aspect to the behavior.

Staddon (1977) further clarified the nature of these induced behaviors by separating the behavior occurring within an interval into three classes. "Interim" behavior typically occupies the first third of moderately long intervals and is exemplified by polydipsia. This class is essentially identical to the class termed ad- 
junctive by Falk (1971). Staddon labeled the behavior which typically occupies the last third of moderately long intervals as "terminal" behavior. This behavior is exemplified by magazine approach. The third class of behavior can occur in the middle portion of the intervals. These "facultative" behaviors are not so much induced by the schedule as they are normally occurring behaviors which occur when not displaced by the more dominant behaviors which occur in the early (adjunctive behavior) and late (terminal behavior) portions of the interval.

Within both Falk's and Staddon's framework, spot pecking is clearly an adjunctive behavior, and would therefore be expected to have functional similarities to polydipsia and other adjunctive behaviors. This is true with respect to its development over a few days' exposure to the generating schedule, its temporal distribution of occurrence, its seemingly excessive nature, and its dependence on the primary schedule of food deprivation and food occurrence. Spot pecking is dissimilar, however, when considering its roughly all-or-none relationship with deprivation and its reliable occurrence in very long interval schedules. Neither of these differences seem crucial though, considering the present level of precision associated with the specification of the factors governing adjunctive behaviors.

The emphasis that an analysis of spot pecking brings to the study of induced behaviors involves the relationship between the appetitive and/or consummatory behavior maintained by the generator schedule and the obtained adjunctive behavior. The similarity of adjunctive spot pecking to foraging and eating is particularly clear. In addition to its strong topographical similarity, the temporal locus of adjunctive spot pecking within the very long 24 -h interval emphasizes its similarity to the behavior maintained by the generator schedule. Spot pecking rarely occurs in the $20 \mathrm{~h}$ preceding food, and it is generally initiated within 5 min after eating if it occurs at all. The importance of this relationship between the obtained adjunctive behavior and behavior appropriate to the generator schedule is supported by data presented by Falk (1971) and Freed and Hymowitz (1969). They found that eating-like behaviors, that is, paper shredding and manipulating, could displace polydipsic drinking in a schedule maintained by food.

It could be argued that pecking when food deprived and in a situation which was likely to contain food would result in an increased probability of finding and subsequently consuming food. This would, in all likelihood, result in relative reproductive success which would, in turn, increase the frequency of its genetic elements. The literature and casual observation of free-ranging pigeons lend some support to this notion. The literature suggests that: (1) pigeons generally feed in groups (Emlen, 1955), (2) the behavior of individual pigeons is frequently controlled by the behavior of other pigeons (Davis, 1975), and (3) pigeons generally forage for food by pecking at various objects (Zeigler, Green, \& Lehrer, 1971). Casual observations further suggest that one pigeon finding food in a group of foraging pigeons is frequently sufficient to cause several other pigeons to approach and begin pecking in the same general area. Finally, a bird spot pecking a particular area would occasionally generate spot pecking at the same location in the adjacent bird.

These observations and the data from the present study may be taken to suggest that: (1) pecking is a normal appetitive foraging behavior in pigeons, (2) it is under the control of the deprivation state and the feeding situation, (3) it is not necessarily maintained by its consequences, and (4) it is at least partially under the control of arbitrary stimuli.

\section{REFERENCES}

Azrin, N. H., Hutchinson, R. R., \& Hake, D. F. Extinctioninduced aggression. Journal of the Experimental Analysis of Behavior, 1966, 9, 191-204.

Breland, K., \& Breland, M. The misbehavior of organisms. American Psychologist, 1961, 16, 681-684.

Breland, K., \& Breland, M. Animal behavior. New York: Macmillan, 1966.

Brown, P. L., \& Jenkins, H. M. Auto-shaping of the pigeon's key-peck. Journal of the Experimental Analysis of Behavior, $1968,11,1-8$.

Davis, M. J. Socially induced flight reactions in pigeons. Animal Behaviour, 1975, 23, 597-601.

Deadwyler, S. A., \& Segal, E. F. Determinants of polydipsia: VI. Removing the drinking solution midway through the DRL session. Psychonomic Science, 1965, 3, 185-186.

Duncan, I. J. H., \& Woou-Gush, D. G. M. Frustration and aggression in the domestic fowl. Animal Behaviour, 1971, 19, 496-500.

EMLEN, J. T., JR. The study of behavior in birds. In A. Wolfson (Ed.), Recent studies in avian biology. Urbana: University of Illinois Press, 1955.

FaGen, R. M.. \& Goldman, R. N. Behavioural catalogue analysis methods. Animal Behaviour, 1977, 25, 261-274.

FALK, J. L. Production of polydipsia in normal rats by an intermittent food schedule. Science, 1961, 133, 195-196.

FALK, J. L. The nature and determinants of adjunctive behavior. Physiology \& Behavior, 1971, 6, 577-588.

FALK, J. L. The origin and functions of adjunctive behavior. Animal Learning \& Behavior, 1977, 5, 325-335.

Ferster, C. B., \& Skinner, B. F. Schedules of reinforcement. Englewood Cliffs, N.J: Prentice-Hall, 1957.

FlynN, W. E., \& Tedford, W. H., JR. Stereotyped behavior during spaced responding: Mediation vs. superstition. Psychological Record, 1976, 26, 553-556.

Freed, E. X., \& Hyмowitz, N. A fortuitous observation regarding "psychogenic" polydipsia. Psychological Reports, 1969, 24, 224-226.

Hearst, E., \& Jenkins, H. M. Sign-tracking: The stimulusreinforcer relation and directed action. Austin, Tex: Psycho. nomic Society, 1974.

HEDIGER, H. Studies of the psychology and behavior of captive animals in zoos and circuses. New York: Dover Publications, 1968. (Originally published, London: Butterworths Scientific Publications, 1955.)

KEIPER, R. Causal factors of stereotypes in caged birds. Animal Behaviour, 1969. 17, 114-119. 
Kuo, Z. Y. The dynamics of behavior development. New York: Random House, 1967.

LEVy, D. M. On instinct-satiation: An experiment on the pecking behavior of chickens. Journal of General Psychology, 1938, 18, 327-348.

MAIER, R. A., \& MAIER, B. M. Comparative animal behavior. Belmont, Calif: Brooks/Cole, 1970.

Moore, B. R. The role of directed Pavlovian reactions in simple instrumental learning in the pigeon. In R. A. Hinde \& J. Stevenson-Hinde (Eds.), Constraints on learning. New York: Academic Press, 1973.

Nissen, N. W. Individuality in the behavior of chimpanzees. American Anthropologist, 1956, 58, 407-413.

PALYA, W. L. Light-cycle controlled weight changes in pigeons. Journal of Interdisciplinary Cycle Research, 1976, 7, 113-117.

Palya, W. L. Inexpensive pigeon cages. Behavior Research Methods \& Instrumentation, 1977, 9, 312-313.

RUSAK, B., \& ZUCKER, I. Biological rhythms and animal behavior. Annual Review of Psychology, 1975, 26, 137-171.

Sargent, T. D., \& Keiper, R. R. Stereotypies in caged canaries. Animal Behaviour, 1967, 15, 62-66.

Schwartz, B., \& Gamzu, E. Pavlovian control of operant behavior. In W. K. Honig \& J. E. R. Staddon (Eds.), Hand- book of operant behavior. Englewood Cliffs, N.J: PrenticeHall, 1977.

Segal, E. F., \& Deadwyler, S. A. Determinants of polydipsia: VI. Taste of the drinking solution on DRL. Psychonomic Science, 1965, 3, 101-102.

Simpson, M. J. A., \& Simpson, A. E. One-zero and scan methods for sampling behaviour. Animal Behaviour, 1977, 25, 726-731.

Staddon, J. E. R. Schedule-induced behavior. In W. K. Honig \& J. E. R. Staddon (Eds.), Handbook of operant behavior. Englewood Cliffs, N.J: Prentice-Hall, 1977.

Staddon, J. E. R., \& Simmelhag, V. L. The "superstition" experiment: A re-examination of its implications for the principles of adaptive behavior. Psychological Review, 1971, 78, 3-43.

Zeigler, H. P. Feeding behavior of the pigeon. Advances in the Study of Behavior, 1976, 7, 285-389.

Zeigler, H. P., Green, H. L., \& Lehrer, R. Patterns of feeding behavior in the pigeon. Journal of Comparative and Physiological Psychology, 1971, 76, 468-477.

(Received for publication October 19, 1978; revision accepted September 12, 1979.) 